\title{
Temporal distribution of blood donations in three Brazilian blood centers and its repercussion on the blood supply
}

\author{
Claudia Di Lorenzo Oliveira ${ }^{1}$ \\ Cesar de Almeida-Neto² \\ Emily Jing Liu ${ }^{3}$ \\ Ester Cerdeira Sabino ${ }^{4}$ \\ Silvana Carneiro Leão ${ }^{5}$ \\ Paula Loureiro ${ }^{5,6}$ \\ David Wright ${ }^{3}$ \\ Brian Custer $^{7}$ \\ Thelma Therezinha Gonçalez ${ }^{7}$ \\ Ligia Capuani² \\ Michael Busch ${ }^{7}$ \\ Anna Bárbara de Freitas Carneiro Proietti ${ }^{8}$
}

'Universidade Federal de São João del-Rei UFSI, São João del-Rei, MG, Brazil

${ }^{2}$ Fundação Pró-Sangue - Hemocentro de São

Paulo, São Paulo, SP, Brazil

${ }^{3}$ Westat Inc., San Francisco, CA, USA

${ }^{4}$ Universidade Federal de São Paulo -

UNIFESP, São Paulo, SP, Brazil

${ }^{5}$ Fundação de Hematologia e Hemoterapia de Pernambuco -

HEMOPE, Recife, PE, Brazil

${ }^{6}$ Universidade de Pernambuco - UPE, Recife, PE, Brazil

'Blood Systems Research Institute - BSRI, San Francisco, CA, USA

${ }^{8}$ Universidade Federal de Minas Gerais -

UFMG, Belo Horizonte, MG, Brazil

Conflict-of-interest disclosure:

The authors declare no competing financial interest

Submitted: 10/31/2012

Accepted: 1/27/2013

Corresponding author:

Claudia Di Lorenzo Oliveira

Universidade Federal de São João del-Rei - UFS

Av Sebastião Gonçalves Coelho, 400 -

Chanadour

35501-296 Divinópolis, MG, Brazil

Phone: 5537 3221-1626

claudia.dlorenzo@gmail.com

www.rbhh.org or www.scielo.br/rbhh
Background: Seasonal distribution of blood donation hinders efforts to provide a safe and adequate blood supply leading to chronic and persistent shortages. This study examined whether holidays, geographical area and donation type (community versus replacement) has any impact on the fluctuation of donations.

Methods: The numbers of blood donations from 2007 through 2010 in three Brazilian Retrovirus Epidemiological Donor Study II (REDS-II) participating centers were analyzed according to the week of donation. The weeks were classified as holiday or non-holiday. To compare donations performed during holiday versus non-holiday weeks, tabulations and descriptive statistics for weekly donations by blood center were examined and time series analysis was conducted.

Results: The average weekly number of donations varied according to the blood center and type of week. The average number of donations decreased significantly during Carnival and Christmas and increased during the Brazilian National Donor Week. The fluctuation was more pronounced in Recife and Belo Horizonte when compared to São Paulo and higher among community donors.

Conclusion: National bank holidays affect the blood supply by reducing available blood donations. Blood banks should take into account these oscillations in order to plan local campaigns, aiming at maintaining the blood supply at acceptable levels.

Keywords: Blood donors; Temporal distribution; Blood banks; Holidays; Time factors; Brazil

\section{Introduction}

Known to everyone who works in blood banks, the number of donations fluctuates over time, leading to varying periods of abundance and shortage within the blood supply ${ }^{(1)}$. Having an excess of stored blood may result in a loss due to expired shelf life while a lack of blood may result in postponed surgeries and transplants, for example, and eventually loss of lives. This poses challenges to blood centers to recruit and retain enough donors and strategically collect sufficient blood components for a given recipient population ${ }^{(2-4)}$.

When blood donations and therefore blood stocks decrease to critical levels, blood centers in most countries, including Brazil, take measures to increase donations rapidly through appeals to regular donors and the communication using different media (newspaper, $\mathrm{TV}$ or radio campaigns). There are also regular activities to stimulate donation, such as the National Donor Week, mobile collections, phone calls, text messages and social networks (Facebook, Twitter, etc.).

Few papers have analyzed the seasonal variation of donation distribution in the world. Crawford et al.$^{(5)}$ evaluated weekly donation rates from 1995 to 2005 among three Red Cross donor regions in the USA and found a great deal of variation, particularly among younger donors. However, most of the studies correlate donation variation with natural catastrophes, such as the earthquake in China ${ }^{(6)}$, terrorist attacks, such as September Eleven $^{(7)}$, or viral epidemics, like influenza outbreaks ${ }^{(8)}$.

To our knowledge, no study in Brazil or other Latin America countries has examined donation fluctuations along the year, encompassing bank holidays, when such reductions are usually more pronounced. Nor is it known how successful blood center's recruitment efforts are improving donation activity. Examining the annual donation fluctuation could help identify when donations may decline to a point at which stocks are threatened, whether and how effectively donation campaigns increase donation and, to define the type of donors that are most likely to donate during bank holiday weeks and recruitment campaigns.

The present study examined the temporal distribution of weekly donations during four years in three blood centers in Brazil and compared weeks with bank holidays and those without ('typical' weeks), trying to understand how they varied among the three blood centers. The hypothesis is that the variation in the number of donations is related to bank holidays and celebrations such as the National Donor Week, as well as to campaigns for donations during the period of study. 


\section{Methods}

All blood donations in 2007 through 2010 of the data warehouse established for the Retrovirus Epidemiological Donor Study II in three Brazilian blood centers were studied: Fundação Pró-Sangue (FPS) in São Paulo State (southeastern region), Fundação Centro de Hematologia e Hemoterapia de Minas Gerais (Hemominas), in Minas Gerais State (southeastern region) and Fundação de Hematologia e Hemoterapia de Pernambuco (HEMOPE) in Pernambuco State (northeastern region) $)^{(9,10)}$.

To analyze the fluctuation in weekly number of donations, a 'calendar week' was defined as a week beginning on a Sunday and ending on a Saturday. A holiday week was defined as a week in which there was at least one bank holiday during the week. If there was no bank holiday during the week, that week was defined as a non-holiday week ('typical'). Altogether, there were 11 holiday weeks and 41 non-holiday weeks in Recife and São Paulo in each year, in Belo Horizonte there were 12 holiday weeks and 40 non-holiday weeks. Week order was assigned from the first calendar week of 2007 to the last calendar week of 2010. A total of 208 weeks were analyzed. Data was also collected about local blood donation campaigns during the years of 2007 , 2008 and 2009 in the three blood banks.

\section{Statistical analysis}

To compare donations, tabulations and descriptive statistics for weekly donations by blood center were examined for specific decreases and increases during holiday and campaign weeks and compared to other weeks. Time series regression analysis was conducted to examine the impact of bank holidays and campaigns on blood donations at each blood center by type of week (holiday or non-holiday), including the National Donor Week. This time series modeling uses information from previous weeks to predict the current number of donations at each blood center. The model with Lag 1 (one week prior) and Lag 2 (two weeks prior) was selected for the three centers and the effects of holiday weeks and the National Donor Week on donations were examined. The National Donor Week was not included among the holiday weeks. All analyses were performed by blood center due to the fact that there were different local bank holidays and blood centers had different operation schedules.

\section{Campaigns for blood donation and vaccination}

In Belo Horizonte recruitment media campaigns occurred in the following weeks: 2007 - Weeks 19, 26 and 31; 2008 Weeks 10, 22, 35, 37 and 42; 2009 - Weeks 2,5 and 10. In São Paulo, the blood center keeps regular campaigns in the press and on radio. The months in 2008 with higher numbers of press and radio advertisements were January (Weeks 1-5) and May (Weeks 19-22). In 2009, July was the month with the highest number of advertisements (Weeks 27-30). In Recife, every year four campaigns are held by the blood center, one before the Carnival, around Weeks 4-7, another in March, called Lives for Lives (Weeks 12,13 and 14 in 2007; Weeks 8 and 9 in 2008 and Weeks 12 and 13 in 2009). During June they have the festival of São João and in November the National Donor Week.
Also, two national vaccination campaigns are conducted in Brazil, against influenza (May, 2007 and 2008) and measles (July to September, 2008). The Belo Horizonte blood center conducted recruitment campaigns before the beginning of vaccination against measles in 2008 to encourage young donors to donate before receiving the vaccine.

\section{Results}

From January 2007 to December of 2010, over 1.2 million donation visits were made to the three blood centers - 539,735 (43.3\%) in São Paulo, 285,907 (22.9\%) in Belo Horizonte and 420,820 (33.8\%) in Recife. For all centers combined, the mean number of donations during a holiday week was 1753 compared to 2021 in a typical week. Figure 1 shows the fluctuation in the number of blood donations over time at the three REDS-II Brazil blood centers in 2008 . The average weekly number of donations was higher for São Paulo and lower for Belo Horizonte. In the beginning and the end of the year, i.e. between Christmas and the first week of the following year, there was a clear drop in donations at all centers (Figures 1 and 2). Another marked decrease was found around Weeks 6-8 which marks the Carnival holidays in Brazil. Also, an increase in donations can be seen within Weeks 44-48, which approximately corresponds to the National Donor Week. This event varies according to the year, but occurs around November $25^{\text {th }}$, the National Donor Day in Brazil.

There were significant differences in donation number/rates comparing weeks with and without bank holidays in Recife and Belo Horizonte, but not in São Paulo. As shown in Table 1, an analysis, comparing donations for all three centers, confirmed that there are more donations in non-holiday weeks compared to holiday weeks (2021 donations versus 1753; p-value $<0.01$ ). When donations at the three centers were examined separately, significant differences between holiday and non-holiday weeks were found for Recife and Belo Horizonte (p-value < 0.001 ) but, although there was a trend to more donations during non-holiday weeks in Sao Paulo, the difference was not significant ( $\mathrm{p}$-value $=0.06$ ).

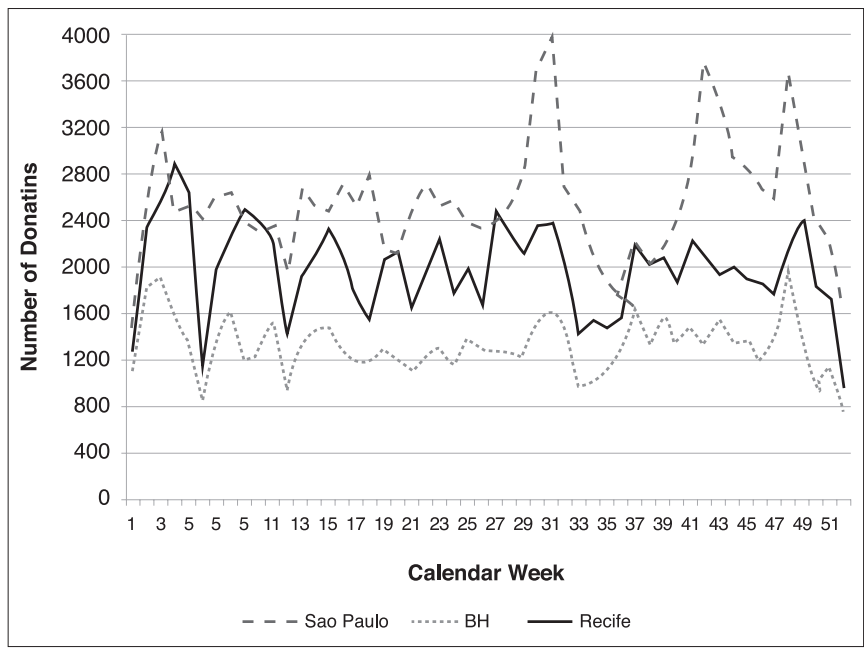

Figure 1 - Fluctuations in the number of donations at three Brazilian blood centers by calendar week in 2008 

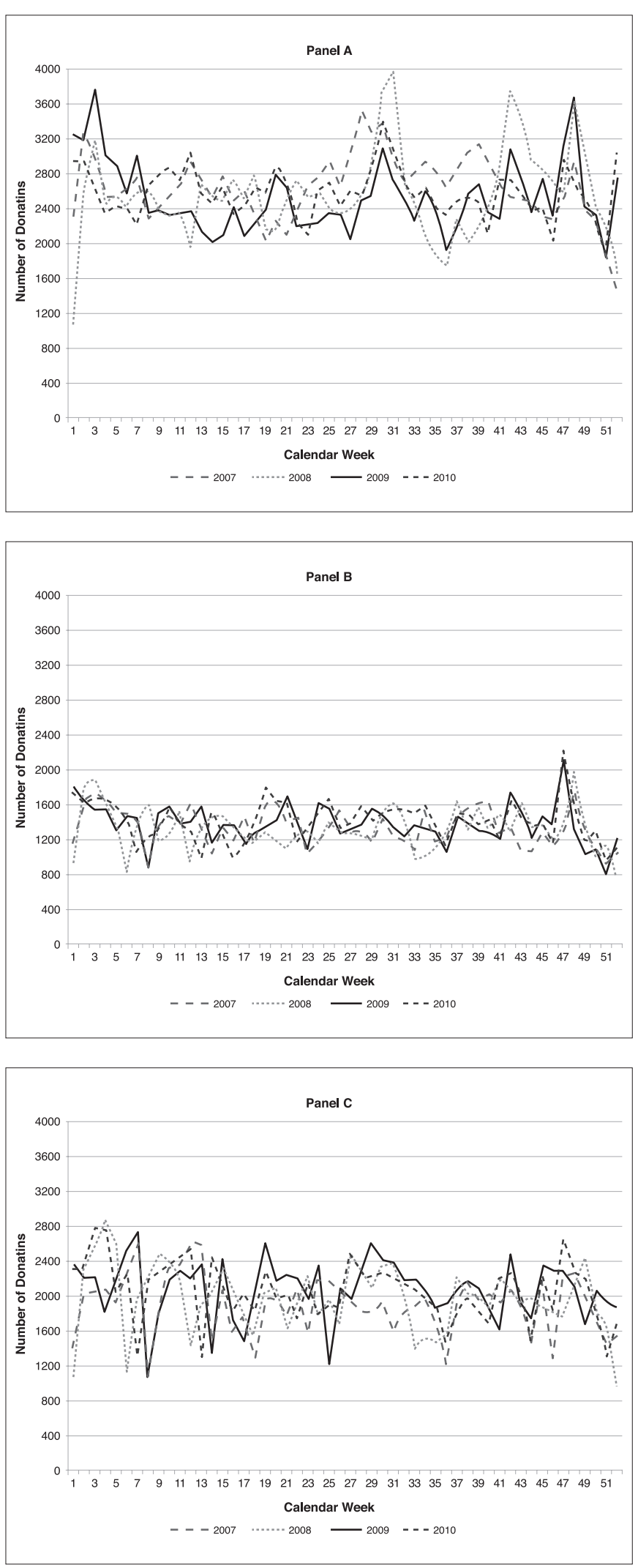

Figure 2 - Blood donation fluctuations across calendar weeks from 2007 to 2010 in Sao Paulo (A), Belo Horizonte (B) and Recife (C)
Table 1 - Average weekly donations during holiday and non-holiday weeks by center

\begin{tabular}{llrlrl}
\hline \multirow{2}{*}{ Center } & \multicolumn{2}{c}{$\begin{array}{c}\text { Holiday weeks } \\
(\mathbf{n}=\mathbf{2 2})\end{array}$} & \multicolumn{2}{c}{$\begin{array}{c}\text { Non-holiday weeks } \\
(\mathbf{n}=\mathbf{8 2})\end{array}$} & \multirow{2}{*}{ p-value } \\
\cline { 2 - 5 } & Mean (SD) & \multicolumn{1}{c}{ Range } & Mean $(\mathbf{S D})$ & \multicolumn{1}{c}{ Range } & \\
\hline Recife & $1691(501)$ & $948-2636$ & $2023(293)$ & $1277-2888$ & $<0.001$ \\
Belo & & & & & \\
Horizonte & $1179(215)$ & $750-1646$ & $1380(215)$ & $927-1987$ & $<0.001$ \\
$\quad$ São Paulo & $2440(510)$ & $1433-3765$ & $2644(426)$ & $1743-3993$ & 0.06 \\
All centers & $1753(671)$ & $750-3765$ & $2021(609)$ & $927-3993$ & $<0.01$ \\
\hline
\end{tabular}

The possibility that holiday weeks were always associated with the least amount of donations was examined, and whether campaigns had an impact on the number of donations. This was done by comparing the 12 weeks in 2007 and 2008 with the lowest number of donations (approximately three months) and the 12 weeks that had the highest number, by center (Table 2). The 12 weeks with the highest number of donations had on average twofold more donations than the 12 weeks with the lowest amount of donations.

Among the 12 weeks with the least number of donations, over half of the weeks in Recife (eight weeks) and Minas Gerais (seven weeks) were holiday weeks. In São Paulo, where no significant differences in the number of donations were found between holiday and non-holiday week, only four out of the 12 weeks with the lowest number of donations were holiday weeks. Interestingly, four calendar weeks (Weeks 51 and 53 in 2007 and Weeks 12 and 52 in 2008) reported a low quantity of donations in all blood centers. Among the 12 weeks with the highest number of donations, only a few calendar weeks had a holiday (three weeks in Recife and one week in Belo Horizonte and São Paulo). The third week of January, 2008 (Week 3) showed a high number of donations in all blood centers (Table 2).

Table 2 - Twelve weeks with the lowest and highest number of donations in 2007 and 2008 in chronological order by center

\begin{tabular}{|c|c|c|c|c|c|c|}
\hline & \multicolumn{3}{|c|}{$\begin{array}{l}\text { Weeks with the lowest } \\
\text { number of donations }\end{array}$} & \multicolumn{3}{|c|}{$\begin{array}{l}\text { Weeks with the highest } \\
\text { number of donations }\end{array}$} \\
\hline & Recife & $\begin{array}{c}\text { Belo } \\
\text { Horizonte }\end{array}$ & $\begin{array}{c}\text { São } \\
\text { Paulo }\end{array}$ & Recife & $\begin{array}{c}\text { Belo } \\
\text { Horizonte }\end{array}$ & $\begin{array}{c}\text { São } \\
\text { Paulo }\end{array}$ \\
\hline \multirow{7}{*}{2007} & 1 & $8^{*}$ & 19 & $7 *$ & 2 & 2 \\
\hline & $8^{*}$ & 14 & 21 & 11 & 3 & 28 \\
\hline & $18^{*}$ & 23 & 51 & $12^{*}$ & 4 & 29 \\
\hline & $36^{*}$ & 51 & $52 *$ & 13 & 20 & 30 \\
\hline & $44 *$ & $52 *$ & & & 39 & 38 \\
\hline & 46 & & & & 40 & 39 \\
\hline & 51 & & & & 48 & 3 \\
\hline \multirow{8}{*}{2008} & $1^{*}$ & $1 *$ & $1^{*}$ & 3 & 2 & 30 \\
\hline & $6^{*}$ & $6^{*}$ & $12 *$ & 4 & 3 & 31 \\
\hline & $12 *$ & $12 *$ & 20 & $5^{*}$ & 31 & $42 *$ \\
\hline & 33 & 33 & 34 & 9 & $37 *$ & 43 \\
\hline & $52 *$ & 34 & 35 & 10 & 48 & 48 \\
\hline & & $50^{*}$ & 36 & 27 & & \\
\hline & & $52^{*}$ & 38 & 31 & & \\
\hline & & & $52 *$ & 49 & & \\
\hline Average & 1268 & 953 & 1823 & 2544 & 1729 & 3456 \\
\hline
\end{tabular}


Week 48, which was the National Donor Week in 2008, had the highest number of donations in Belo Horizonte. In Recife and São Paulo, however, the highest number of donations came earlier in the year (Week 3 in Recife and Week 31 in São Paulo). No drastic increase in the weekly donations was found in the National Donor Week in 2007 (Week 47) however Week 48 had the highest number of donations in Belo Horizonte.

Different temporal patterns for donation comparing community and replacement donors were seen for all of the three blood centers. Replacement donors showed less fluctuation than donations from community donors in Belo Horizonte and Sao Paulo, but this was different in Recife, where replacement donors varied as much as community donors. Also, in the National Donor Week (Week 47) in Sao Paulo and Belo Horizonte, the number of donations from community donors increased but not for replacement donors. In Recife both types of donations increased (Figure 3).

Time series analysis was conducted for two years (2007/2008) of weekly donation counts for each center (Table 3). An increase in the number of donations was found near the bank holidays and National Donor Week. In Recife and Belo Horizonte, a significant decrease in donations (-344 and -192 donations, respectively; $\mathrm{p}$-value $<0.001)$ was found during calendar weeks with holidays, but not in São Paulo (-88 donations; p-value $=0.23$ ). During the National Donor Week, a significant increase in donations was found in São Paulo (+415 donations; $p$-value $\leq 0.05$ ), but not in Belo Horizonte or Recife ( +252 donations; $p$-value $=0.07$ and +225 donations; $\mathrm{p}$-value $=0.35$, respectively).

\begin{tabular}{|c|c|c|c|}
\hline & $\begin{array}{c}\text { Recife } \\
\text { Mean (SE) }\end{array}$ & $\begin{array}{c}\text { Belo Horizonte } \\
\text { Mean (SE) }\end{array}$ & $\begin{array}{l}\text { Sao Paulo } \\
\text { Mean (SE) }\end{array}$ \\
\hline Intercept & $2016(47.4)$ & $1372(30.7)$ & $2594(93.4)$ \\
\hline Holiday week & $-334.0(79.9) \dagger$ & $-192.3(45.7) \dagger$ & $-87.9(72.8)$ \\
\hline Donor week & $224.5(233.8)$ & $252.3(139.2)$ & $415.4(208.3) *$ \\
\hline
\end{tabular}

$*$ p-value $\leq 0.05$

$\dagger$ p-value $\leq 0.001$

\section{Discussion}

When analyzing the seasonal distribution of donations from 2007 to 2010, decreases in donations related to bank holidays such as Carnival and Christmas and an increase during the Brazilian National Donor Week were observed. The donations fluctuated significantly according to the blood bank and type of week (holiday versus non-holiday). The number and duration of bank holidays varies in each country and, in some places, including Brazil, besides the national holidays there are also local holidays. Many bank holidays in Latin America originate from folkloric and religious traditions and some of them last two or more days. During bank holidays it is very common that families travel to the coast, countryside or mountains to rest and stay out of the large metropolitan areas such as Sao Paulo, Belo Horizonte and Recife. Factories, universities and banks are usually closed during bank holidays; this means that many workers take some days off.
The data of this study support the idea that blood supply tends to drop around bank holidays due to a decrease in blood donations. For example, the period between Christmas and the first day of the following year is often a period when donations decline dramatically. However, the need for blood does not diminish proportionately during these holidays, and may even increase due to a greater incidence of traffic accidents related to vacations, heavy traffic and higher consumption of alcohol ${ }^{(11)}$.

The lack of blood during some bank holidays has motivated Brazilian blood banks to organize campaigns before these events in order to improve the blood supply. In this way, November is the month of the donor and the week around November 25th is the main time for Brazilians to donate blood. Media advertisement with participation of artists and athletes has traditionally been a way to motivate the population to donate blood before the holidays. Also, some blood banks have campaigns before the start of national vaccination periods for young people due to the temporary deferral period after vaccination. In this study, in all blood banks, Week 47 (National Donor Week) had increases of donations, but other local campaigns were not as successful. For example, the blood center in Belo Horizonte performed five media campaigns in 2008, but none of these reported a higher number of donors. In São Paulo, massive blood donation campaigns are frequently programmed before bank holidays and vacations. In 2008 there was a 'fireman' campaign during the winter vacation in July. There were more than 2000 donations, which represented a $30 \%$ increase in collected units compared to the previous year ${ }^{(6)}$. Additionally, before Carnival, direct mails and short message service (SMS) text messages are also sent to increase the number of donations due to the typical decrease in donations experienced during these festivities. In February 2009, this strategy increased the total number of donations by more than 2000 units. In Recife, the campaign 'Lives for Lives' seems to have been more effective than other local campaigns, because the week in which it happened is among weeks with the highest number of donations (Weeks 12 and 13 in 2007 and Week 9 in 2008).

In 2007 , the vaccination campaign against measles occurred between July and September (Weeks 19 to 22). However, contrary to what might be expected that it would affect the blood supply, the data of this study did not confirm this because this period did not include the weeks with the lowest numbers of donations (Table 2). This could be due to low adhesion to the vaccination campaign of people within the donation age range (18-65 years of age). In 2008, the campaign performed before the measles vaccination did not increase the number of donations (Week 30) and, moreover, the vaccination did not affect the blood supply. This observation demonstrates the importance of better planning for campaigns to be more effective.

Bank holidays are a potential problem to blood banks and the present study detected a decrease in donations in all blood banks. However, blood banks are affected in different ways, for example, holidays such as Carnival affected Belo Horizonte and Recife more than São Paulo, whereas Christmas affected all three blood banks. In 2008 the Easter holiday (Week 12) was associated with a low number of donations in all blood banks, including São Paulo, but the same was not observed in 2007 (Week 14). 

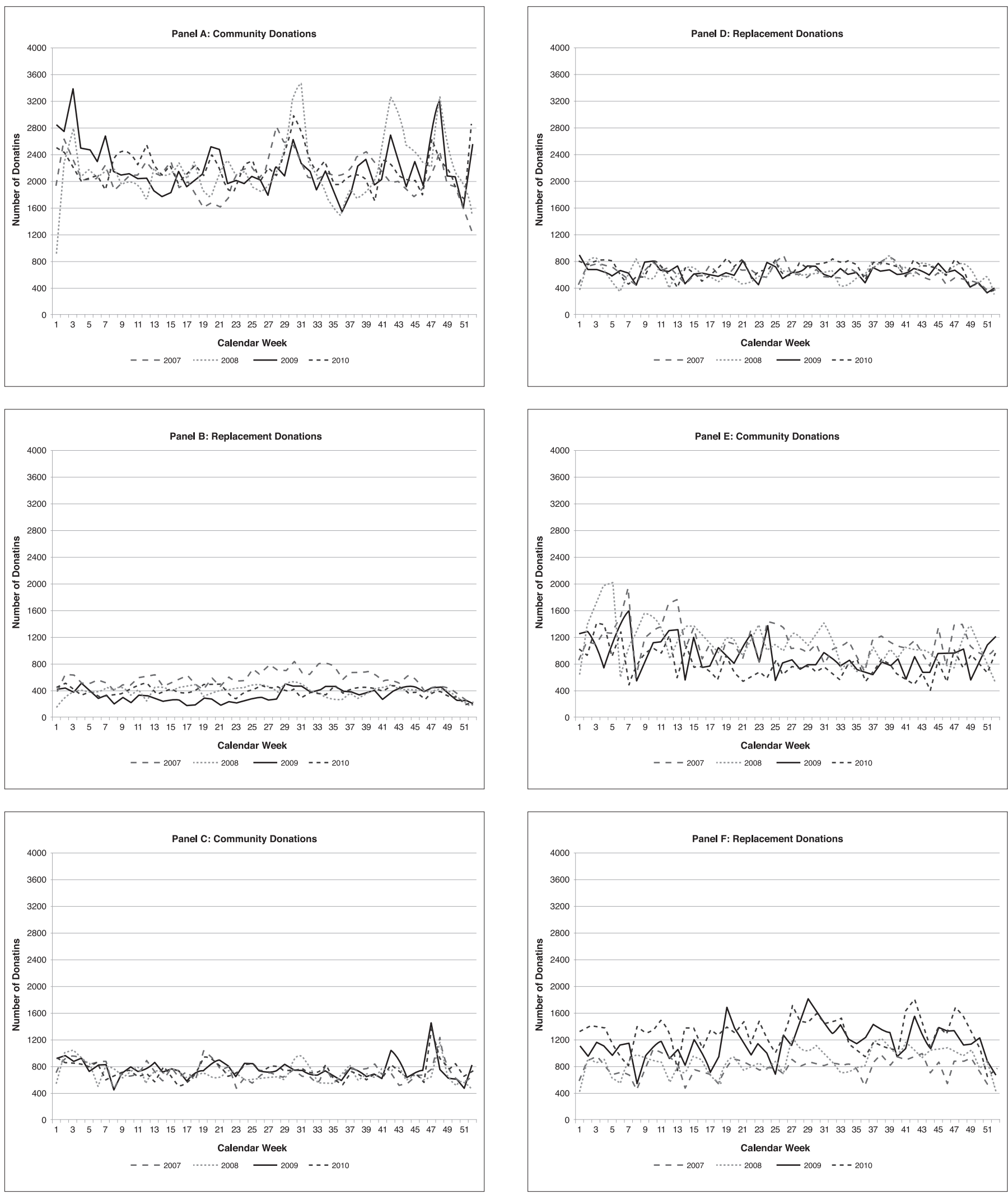

Figure 3 - Temporal pattern of blood donation for community versus replacement donors across calendar weeks from 2007 to 2010 at São Paulo (A \& B), Belo Horizonte (C \& D) and Recife (E \& F) 
Similarly to what was observed in the United States ${ }^{(12)}$, stability in the number of components available in the supply is mostly attributed to repeat donations, since over $60 \%$ of donations are made by repeat donors in Brazili ${ }^{(9)}$. Consequently, the intervals between donations may also have an influence in the stock during periods of blood shortages. During donation campaigns, many repeat blood donors will positively answer to blood center requests. A higher return rate and an earlier return were expected in Quebec among repeat donors when compared to first-time donors ${ }^{(13)}$. According to the Brazilian policy, men are allowed to perform another blood donation only after 60 days and women after 90 days. De Almeida Neto et al. found that the medium time for donor return among the studied centers is approximately 6 months $^{(14)}$. During this period a gap in the number of donations may occur and first-time donors will be needed to fill blood centers' needs. Thus, campaigns should be tailored to focus not just on short-term, but also on the long-term needs. The challenge blood centers face is to develop improved customized communication strategies for recruitment and retention for firsttime and repeat donors.

Glynn et al. ${ }^{(7)}$ studied blood donations after the September $11^{\text {th }}$ terrorist attack and found that the calamity improved the number of first-time donors, but the risk of blood-transmitted infections also increased and the return rates were similar before and after the event. This reinforces the idea that a regular, stable number of donors is very important to adequately keep the blood supply. Seasonal campaigns would be a good opportunity to improve the blood supply in some situations, but regular campaigns to convince healthy first-time donors to return and become regular donors, independently of crisis, are very important to avoid seasonal shortages of blood.

One limitation of the present study was the use of secondary data, for it was not possible to directly ask the donors whether bank holidays or the media campaigns affected their decision to donate blood. Another issue was that there was no standardized protocol to register information about campaigns and advertisements in the blood banks, adding a difficulty to the analysis because of the variation in the recall of information about the number and type of campaigns.

\section{Conclusion}

The fluctuation of blood donations did not follow a predictable pattern in blood banks. Some bank holidays had a great influence in one year but not in others, which poses a challenge to blood banks. Since this is a widespread problem, blood banks worldwide should analyze the number of donations regularly and start a campaign on each warning sign.

\section{Acknowledgements}

This work was supported by the National Heart Lung and Blood Institute, National Institutes of Health, Retrovirus Epidemiology Donor Study-II: International Component. Sabino $\mathrm{EC}$ and Carneiro-Proietti $\mathrm{AB}$ are recipients of $\mathrm{CNPq}$ grants. The authors thank Cissa Nunes Soares for reviewing the manuscript. The authors thank the staff at all participating Brazilian blood centers. The Retrovirus Epidemiology Donor Study - II (REDSII), International Component (Brazil) was the responsibility of: Fundação Pró-Sangue/Hemocentro São Paulo and University of São Paulo (São Paulo).

\section{References}

1. Sandborg E. Getting people to give blood. Vox Sang. 2000;78(Suppl 2):297-301.

2. Ownby HE, Kong F, Watanabe K, Tu Y, Nass CC. Analysis of donor return behavior. Retrovirus Epidemiology Donor Study. Transfusion. 1999;39(10):1128-35.

3. Sebok MA, Notari EP, Chambers LA, Benjamin RJ, Eder AF. Seasonal temperature variation and the rate of donor deferral for low hematocrit in the American Red Cross. Transfusion. 2007;47(5):890-4

4. Notari EP 4th, Zou S, Fang CT, Eder AF, Benjamin RJ, Dodd RY. Agerelated donor return patterns among first-time blood donors in the United States. Transfusion. 2009;49(10):2229-36.

5. Crawford SO, Reich NG, An MW, Brookmeyer R, Louis TA, Nelson KE, et al. Regional and temporal variation in American Red Cross blood donations, 1995 to 2005. Transfusion. 2008;48(8):1576-83.

6. Liu J, Huang Y, Wang J, Bi X, Li J, Lu Y, Wen X, Yao F, Dong X, He W, Huang M, Ma H, Mei H, King M, Wright DJ, Ness PM, Shan H;REDS II International China Study. Impact of the May 12, 2008, Earthquake on blood donations across five Chinese blood centers. Transfusion. 2010;50(9):1972-9.

7. Glynn SA, Busch MP, Schreiber GB, Murphy EL, Wright DJ, Tu Y, Kleinman SH; NHLBI REDS Study Group. Effect of a national disaster on blood supply and safety: the September 11 experience. JAMA. 2003;289(17):2246-53.

8. Kamp C, Heiden M, Henseler O, Seitz R. Management of blood supplies during an influenza pandemic. Transfusion. 2010;50(1):231-9.

9. Carneiro-Proietti AB, Sabino EC, Sampaio D, Proietti FA, Gonçalez TT, Oliveira CD, et al. Demographic profile of blood donors at three major Brazilian blood centers: results from the International REDS-II study, 2007 to 2008. Transfusion. $2010 ; 50(4): 918-25$.

10. Takecian PL, Oikawa MK, Braghetto KR, Rocha P, Lucena F, Kavounis $\mathrm{K}$, et al. Methodological guidelines for reducing the complexity of data warehousedevelopment for transactional blood bank systems. Decision Support Systems [Internet]. 2012 [cited 2013 Dec 21];55(3):728-39. Available from: http://www.sciencedirect.com/science/article/pii/ S0167923613000699

11. Mäkelä $P$, Martikainen $P$, Nihtilä E. Temporal variation in deaths related to alcohol intoxication and drinking. Int J Epidemiol. 2005;34(4):765-71.

12. Custer B, Schlumpf KS, Wright D, Simon TL, Wilkinson S, Ness PM; NHLBI Retrovirus Epidemiology Donor Study-II. Donor return after temporary deferral. Transfusion. 2011;51(6):1188-96.

13. Germain M, Glynn SA, Schreiber GB, Gélinas S, King M, Jones M, et al. Determinants of return behavior: a comparison of current and lapsed donors. Transfusion. 2007;47(10):1862-70.

14. de Almeida Neto C, Mendrone A Jr, Custer B, Liu J, Carneiro-Proietti AB, Leão SA, Wright DJ, Murphy EL, Sabino EC; NHLBI Retrovirus Epidemiology Donor Study-II (REDS-II), International Component. Interdonation intervals and patterns of return among blood donors in Brazil. Transfusion. 2012;52(4):722-8. 